Miguel Zazo Romojaro'

María Soledad Ballabriga Escuer ${ }^{2}$

Almudena Pueyo Artieda²

Clara Zazo Cebollero ${ }^{3}$

Ana Julia García Malinis ${ }^{4}$

Patricia Ledo Blasco ${ }^{5}$

1. Servicio de Urgencias. Hospital General San Jorge. Huesca. España.

2. Unidad de Heridas Crónicas. Hospital Sagrado Corazón de Jesús. Huesca.

3. Unidad de Enfermería Cirugía General. Hospital General San Jorge. Huesca. España.

4. Servicio de Dermatología. Hospital General San Jorge. Huesca. España.

5. Supervisora de Enfermería. Hospital Sagrado Corazón de Jesús. Huesca. España.

${ }^{*}$ Autor para correspondencia.

Correo electrónico: mballabriga@salud.aragon.es (M.S. Ballabriga).

\section{Cronificación de una herida traumática por diversos factores}

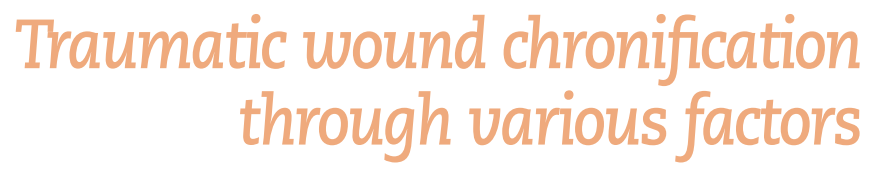

\section{RESUMEN}

Exponemos un caso clínico que nos puede servir como ejemplo y análisis de varios factores que observamos en nuestra práctica diaria. Las diversas circunstancias ocurridas tras el tratamiento inicial, además de las propias dificultades intrínsecas de la herida, hacen que observemos el proceso de curación como un tratamiento sistémico y holístico, además de local.

Reseńaremos un caso en el que, tras un accidente fortuito, se produce una herida compleja. El tratamiento inicial fue realizado mediante técnicas convencionales, pero circunstancias como las creencias religiosas y la mala relación enfermera-paciente desencadenó una mala adhesión al tratamiento, además del uso de alternativas terapéuticas populares. Todo esto acabó en una mala evolución de la herida y la cronificación de la misma. La oportuna derivación a la Unidad de Heridas Crónicas encauzó el tratamiento y la posterior resolución del caso.

PALABRAS CLAVE: Herida traumática, herida aguda cronificada, mala adhesión al tratamiento, relación enfermera-paciente.

\section{ABSTRACT}

We present a case report that serves as an example and analysis of several factors that we observe in our daily practice. The different conditions that occurred after the initial treatment, in addition to the intrinsic difficulties of the wound, make us observe the healing process as a systemic and holistic treatment, as well as a local one.

We will review a case of a complex wound, after a fortuitous accident. The initial treatment was performed using conventional techniques, but religious beliefs and the poor nurse-patient relationship, triggered a bad adherence to treatment and the use of popular therapeutic alternatives. All this ended in a bad evolution and chronification of the wound. Referral to Chronic Wounds Unit, directed the treatment and the resolution of the case report.

KEYWORDS: Traumatic wound, acute chronic wound, poor treatment adherence, nurse-patient relationship.

\section{У HISTORIA CLÍNICA}

Se trata de una mujer de 64 años que vive en un pequeño pueblo eminentemente agrícola. No refiere ni constan antecedentes reseñables. La paciente cuenta que ha salido corriendo al corral de su casa y que se ha enganchado accidentalmente con un apero de labranza (arado tipo cincel). Inmediatamente su hijo la traslada a Urgencias.

\section{Y EXPLORACIÓN}

El estado general estaba conservado. La paciente presentaba cierto nerviosismo. Muy asustada, imploraba constantemente a una imagen de su devoción.

Presentaba herida inciso-contusa, anfractuosa, en región anterointerna del tobillo derecho, con dos colgajos triangulares de base distal (fig. 1).

Tras limpieza y antisepsia, se observa disección sin afectación de la vena safena interna con sección de una rama anterior, por lo que se procede a su ligadura inmediata. Lesión parcial del complejo del tendón tibial anterior de aproximadamente $1 \mathrm{~cm}$ transversal. Se aprecia nervio safeno interno disecado, pero aparentemente íntegro.

Los pulsos distales, el relleno capilar, la sensibilidad y la movilidad del pie y el tobillo eran normales.

La exploración radiológica no mostraba lesiones óseas de evolución aguda.

\section{PROCEDIMIENTOS REALIZADOS}

- Limpieza exhaustiva, antisepsia y ligadura de rama vena safena interna.

- Anestesia local con mepivacaína al $1 \%$.

- Sutura del complejo tendón tibial anterior con Vicryl 3/0. 


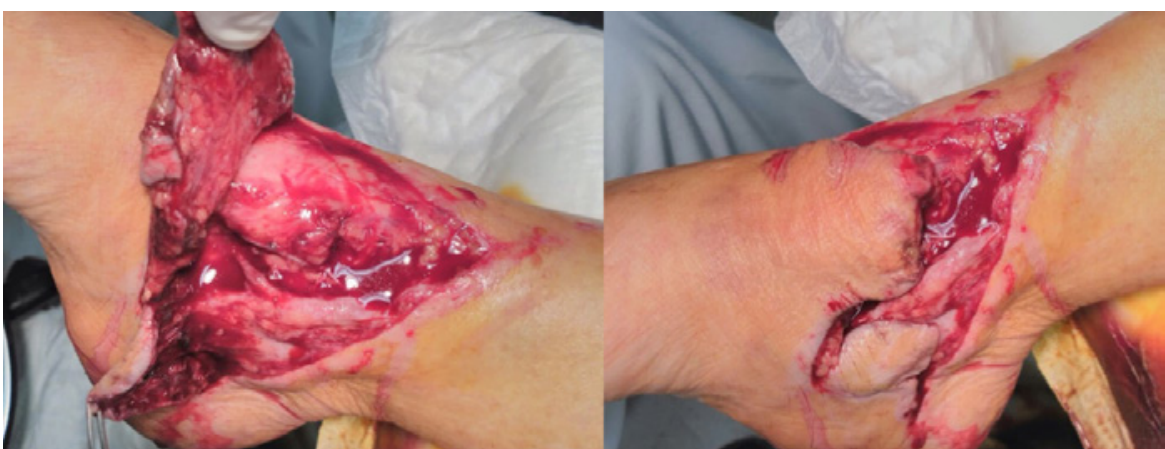

Figura 1. Aspecto de la herida tras limpieza y hemostasia.

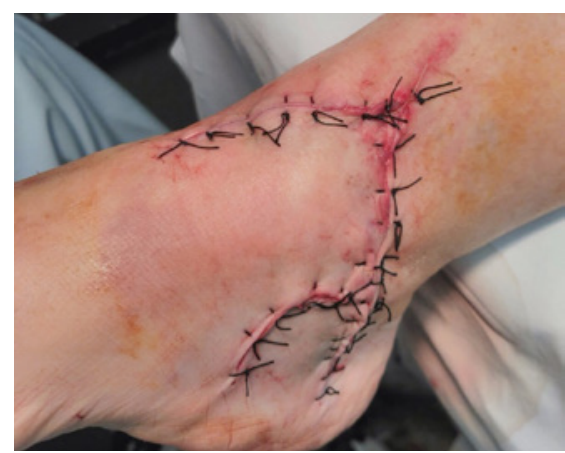

Figura 2. Herida tras los procedimientos en el servicio de urgencias.
- Se realiza sutura sin tensión, para cierre de espacio subcutáneo con Vicryl 3/0, y sutura de la piel con seda 3/0 (fig. 2).

- Inmovilización mediante férula posterior de escayola y compresivo sobre venda de algodón.

- Dosis de vacuna antitetánica.

\section{У PLAN INICIAL DE ACTUACIÓN}

- Inmovilización mediante férula posterior más vendaje compresivo. Extremidad elevada y reposo.

- Antibioterapia (amoxicilina 875 + ácido clavulánico 125) 1/8 h.

- Enoxaparina sódica 40 subcutánea 1/24 h.

Se la instruye sobre los cuidados y se la cita a revisión a las 48 h por su enfermera en el centro de salud.

La paciente pregunta si puede venir a urgencias a curarse en vez de al centro de salud. Ya que esto no es posible, se le insiste en que son importantes las curas y el seguimiento del tratamiento.

\section{У EVOLUCIÓN}

Tras acudir a su centro de salud a revisión tras 48 h, aparentemente la herida presentaba buen aspecto y no había signos de infección. (No se dispone de imagen de este contacto). Se la cita para nueva cura $48 \mathrm{~h}$ después.

Dado que los comentarios tras la primera asistencia nos resultaron sospechosos, desde el Servicio de Urgencias se siguieron los contactos a través de la historia clínica electrónica, observándose que, tras el primer

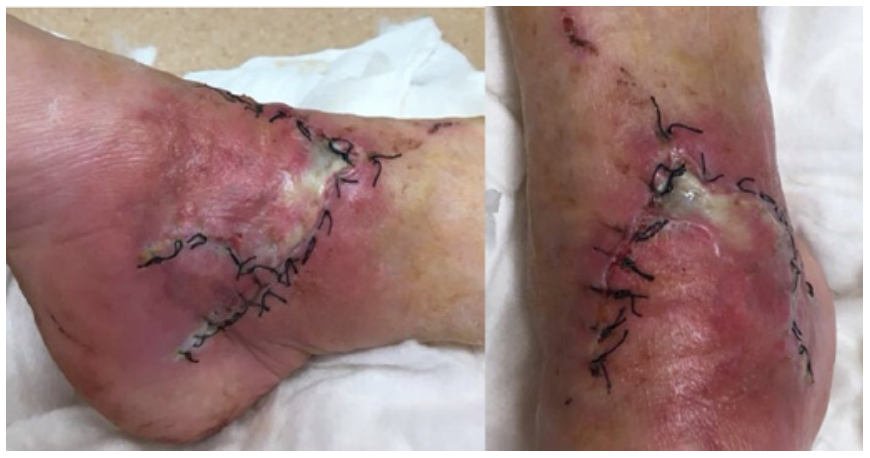

Figura 3. Aspecto de la herida tras una semana de abandono del tratamiento y uso de remedios medicinales no convencionales. contacto, no realizó ninguno más en los 7 días siguientes, por lo que se establece contacto con los compañeros del equipo de atención primaria, para ponerse en contacto telefónico. Esta acude, pero a la consulta de enfermería de atención continuada (era fin de semana), momento en el que reconoce no seguir el tratamiento farmacológico. La venda estaba en muy mal estado y al retirarla se ven restos supuestamente vegetales sobre la herida que tras limpiarla presenta un mal aspecto con zonas muy maceradas y signos de infección (fig. 3).

La paciente reconoce ante la enfermera de atención continuada que no quiere ser tratada por su enfermera, por viejas desavenencias (la enfermera suele insistirle en medidas higiénico-dietéticas y la paciente no se lo toma bien).

Ante esta negativa, la enfermera de atención continuada le retira los puntos de seda y nos comunica la situación. Decidimos, de acuerdo con su médico de cabecera y su enfermera, solicitar cita para cura y seguimiento en la Unidad de Heridas Crónicas (UHC), donde acude el día 15 tras el accidente.

En la UHC se le realiza nueva valoración global y se la interroga por las causas del abandono del tratamiento. Ella cuenta la fe y devoción que siente por una imagen local y que, rezando insistentemente y con medios tradicionales, otras veces se había curado heridas con buenos resultados. No detalla la composición de los medios naturales.

También nos deja entrever la falta de confianza con su enfermera, que, dice, siempre le esta recriminando cosas.

En la exploración de la herida se observa necrosis de los bordes distales que se corresponden con aproximadamente un tercio de la superficie del colgajo más anterior y casi dos tercios del colgajo más medial (figs. 4 a 6).

\section{EVOLUCIÓN EN LA UNIDAD DE HERIDAS CRÓNICAS}

Tras el primer contacto, se observa que por un lado hay una mala evolución de una herida, que ya de por si era complicada, y una desconfianza importante con su equipo médico-enfermera ${ }^{1}$.

Puestos al habla con ellos, nos indican que es un caso difícil y que presenta un mal contacto, por sus costumbres y carácter. Por este motivo y siempre de acuerdo con su equipo de referencia, se procede a realizar el seguimiento desde la UHC, con curas inicialmente cada $48 \mathrm{~h}$.

Por parte de la UHC se entabla un contacto cuidadoso, reforzando constantemente la adhesión al tratamiento y a las curas. Además, y como es habitual, se realiza una valoración integral con registro de la anamnesis, tratamiento farmacológico, valoración de la extremidad, que presenta pulsos pedios conservados, índice tobillo/brazo con re- 


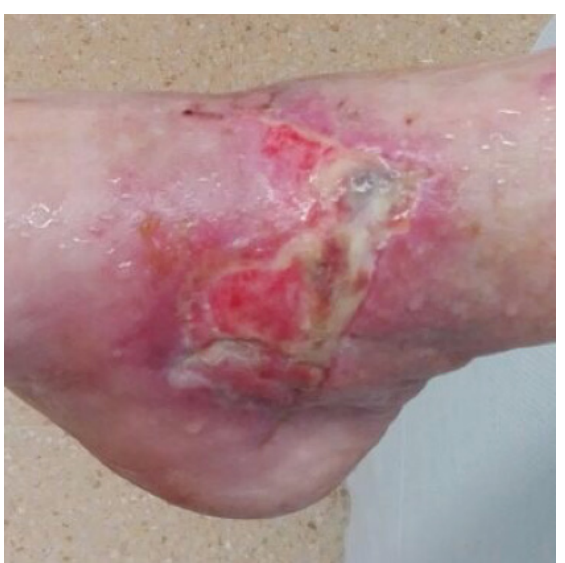

Figura 4. Evolución de la herida en distintas fases del tratamiento en la Unidad de Heridas Crónicas.

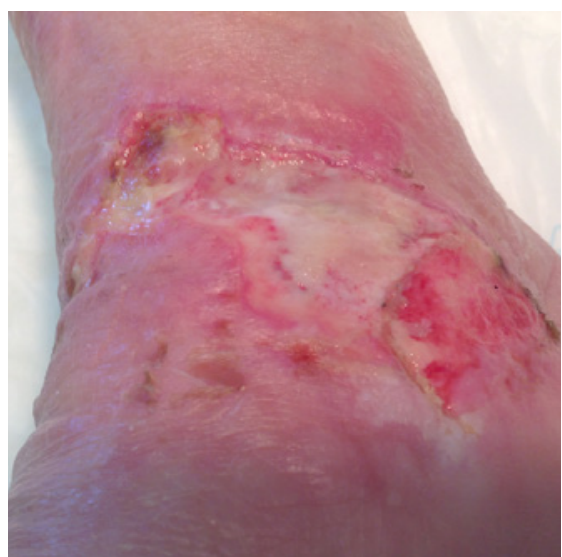

Figura 5. Evolución de la herida según el proceso de cicatrización.

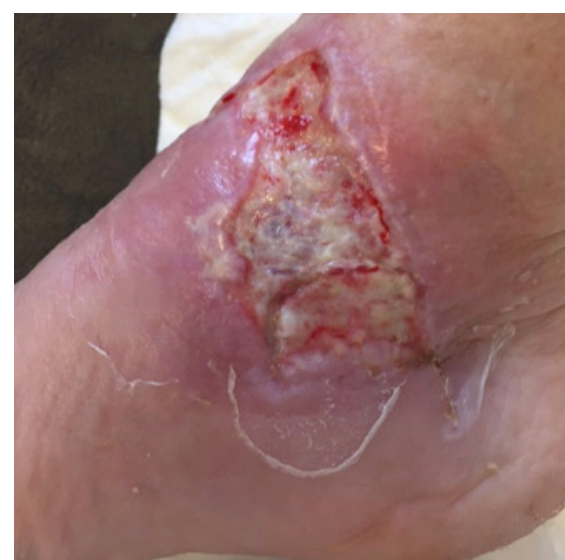

Figura 6. Evolución de la herida según el proceso de cicatrización. sultado de 1 y valoración de la herida que presenta tejido necrótico húmedo y biofilms en el lecho, bordes edematosos y piel perilesional enrojecida.

El tratamiento local se realiza siguiendo el esquema TIME [Tissue (tejido), Infection (infección), Moisture (humedad), Edge (borde)] para la preparación del lecho de la herida²:

- Primero se realiza desbridamiento cortante, retirada mecánica de biofilms y apósito de fibras hidrodetersivas e hidrocelular para conseguir el ambiente húmedo necesario ${ }^{1,3}$.

- Una vez conseguido el desbridamiento se sigue retirando los biofilms bacterianos y se realiza cura local con apósito de plata y silicona.

- En la fase de granulación se observa presencia de tejido de hipergranulación (fig. 7), que sugiere colonización crítica de la herida ${ }^{1,4,5}, y$ se continúa con apósito de plata y aplicación de corticoide tópico.

- Una vez epitelizada la herida, se aplican ácidos grasos hiperoxigenados para su total maduración ${ }^{1}$.

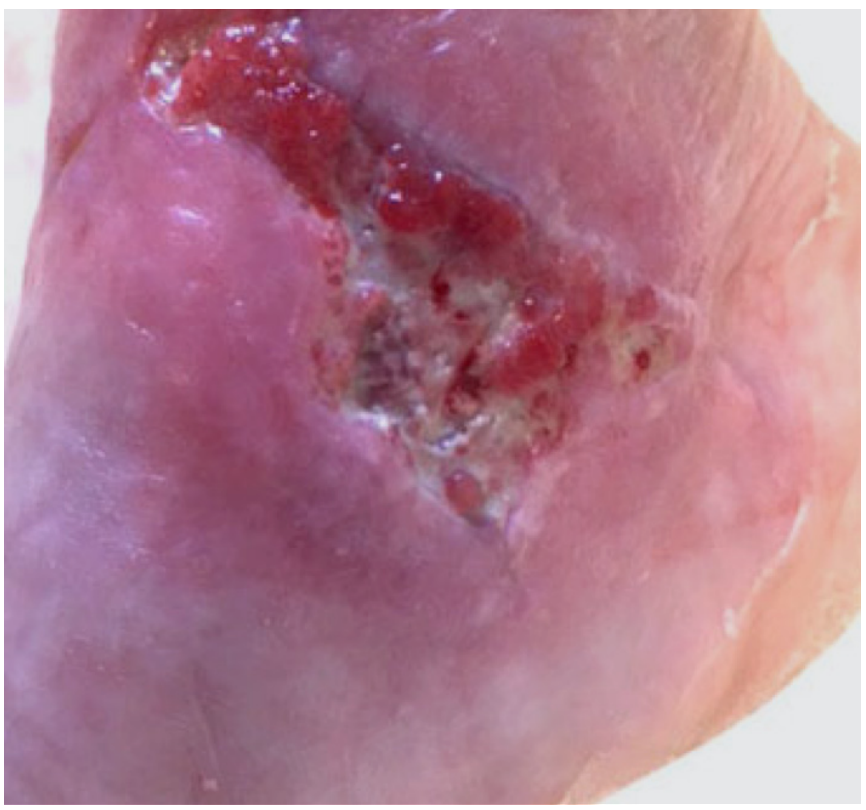

Figura 7. Presencia de tejido de hipergranulación en el lecho ulceral.
- Se le dan los consejos acerca de los cuidados de la cicatriz, protección local, evitar traumatismos directos y exposición solar.

Con nosotros, la paciente se muestra colaboradora y cumple con las indicaciones recomendadas desde la UHC. Aproximadamente a los 90 días del accidente se da el alta de la UHC con resultados satisfactorios del proceso en su conjunto (fig. 8$)^{6}$.

\section{y DISCUSIÓN}

Las heridas traumáticas, como la que nos ocupa en este caso clínico, tienen de por si un pronóstico incierto, ya que las posibles complicaciones pueden detener el proceso de cicatrización ${ }^{1,6-8}$.

Las principales complicaciones locales que se pueden dar en estos casos son:

- Infección.

- Bordes no útiles por el traumatismo.

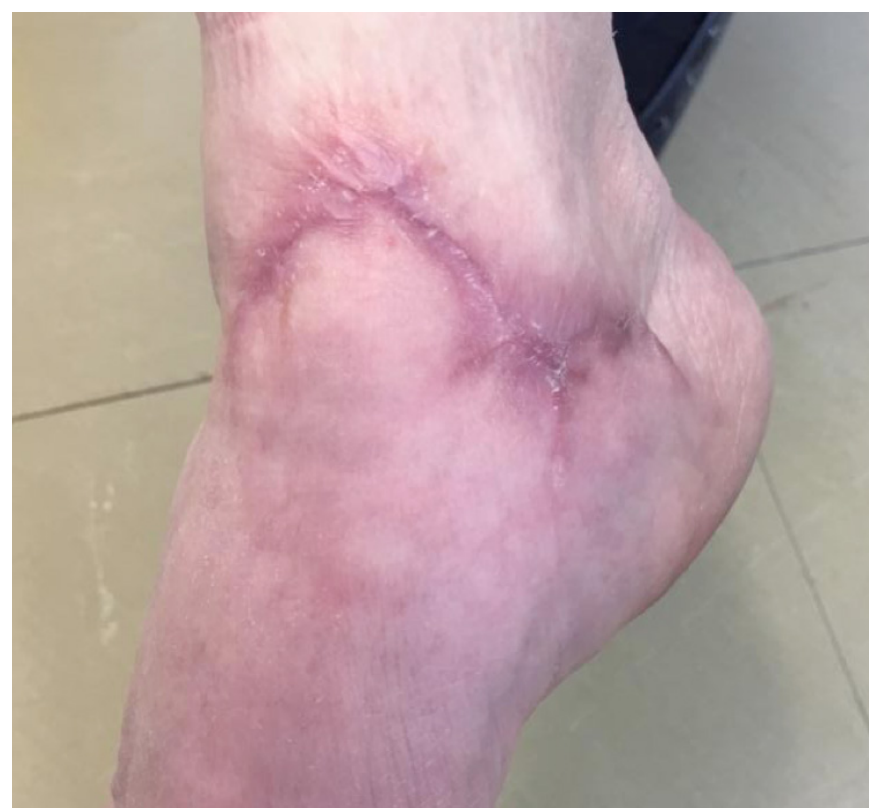

Figura 8. Herida al alta de la Unidad de Heridas Crónicas. 
- Isquemia del colgajo.

- Hematomas.

- Seromas.

- Exceso de presión.

El proceso infeccioso debe prevenirse en todo momento con antibióticos de amplio espectro. Asimismo, los bordes se han de revisar, y si no fueran viables, se realizará curetaje o desbridamiento de los mismos.

Los hematomas, seromas y el exceso de presión, además de prevenirlos, en cada revisión es importante tenerlos en cuenta para actuar con prontitud.

En cuanto a la isquemia del colgajo, debemos tener en cuenta que en las heridas traumáticas no podemos elegir la anatomía de los colgajos y pedículos, y por tanto a veces (como en nuestro caso) los angiosomas no nos son favorables. En estos casos debemos esperar que, si los plexos dérmico y subdérmico del colgajo no fueran competentes, el plexo vascular fasciocutáneo pueda compensar y llegar a realizar una angiogénesis que permita la mayor recuperación y viabilidad del colgajo. Si esto no fuera así, tenemos que estar atentos para solucionar posibles problemas isquémicos ${ }^{6,9}$.

En cuanto a las posibilidades de mejora de la perfusión tisular, se describen métodos a usar como son:

- Inmovilización de la herida.

- Procesos de disminución de la viscosidad sanguínea:

- Heparina de bajo peso molecular.

- Corticoides.

- Antiagregantes.

- Pentoxifilina.

- Fibrinolíticos.

En el caso que describimos, también se observa una mezcla de problemas por las creencias de la paciente y su rechazo a los sanitarios que tiene asignados.

A veces puede resultar difícil conciliar creencias populares o religiosas con las prácticas médicas convencionales. Rezos, novenas y otras actividades religiosas no son negativas para la evolución de una herida. Sin embargo, el uso de remedios tradicionales puede empeorar el pronóstico de una herida.
No es infrecuente ver el uso de azúcar o miel en la práctica diaria. Y no suele ser perjudicial. Sin embargo, el uso de ciertos lodos o barros y cataplasmas de origen vegetal no ofrecen ninguna garantía, además de la posible sobreinfección de la herida ${ }^{10}$.

La relación médico-enfermera-paciente es fundamental en múltiples facetas sanitarias, pero en la adhesión al tratamiento es imprescindible.

De vez en cuando, los propios profesionales no nos damos cuenta de las necesidades particulares, y a veces peculiares, de cada caso. Vamos rápido y en ocasiones enfocamos los tratamientos y los consejos de forma estándar. Es importante tener en cuenta la realidad de que cada persona es diferente y sus necesidades, distintas. No podemos pensar que el paciente es el que se tiene que adaptar a nosotros y no nosotros a él. Ese esfuerzo tiene que formar parte de nuestro trabajo. Y cuando los consejos básicos o habituales no sean bien recibidos, debemos reflexionar sobre el enfoque de cada caso. Por supuesto, sin hacer dejación de nuestras funciones. En el caso que nos ocupa, los consejos eran imprescindibles, ya que se trataba de corregir importantes problemas de salud.

\section{$\checkmark$ CONCLUSIONES}

1. Toda herida puede cronificarse por sus características intrínsecas y/o por la ausencia de cuidados apropiados.

2. Es importante estar alerta cuando sospechemos que un paciente no va a seguir correctamente nuestras indicaciones.

3. La coordinación entre niveles asistenciales ha de ser fluida y debe estar regulada. No debe dejarse exclusivamente en manos de la buena voluntad de los profesionales.

4. Las UHC son complementarias para casos complejos y también pueden ser la alternativa en casos problemáticos

\section{Conflicto de intereses}

Los autores declaran que no hay conflictos de intereses al redactar el presente manuscrito.

\section{У BIBLIOGRAFÍA}

1. Allué Garcia MA, Ballabriga Escuer MS, Clerencia Sierra M, Gállego Domeque L, García Espot A, Moya Porté MT. Heridas

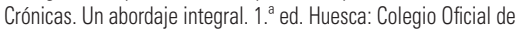
Enfermería de Huesca; 2012

2. Hernández Ortiz JA, Morales Rodríguez J, Navarro Fernández AM, Perea Ruiz J, Padilla Sánchez F, Cordón Llera J. Herida traumática de difícil cicatrización. Gerokomos. 2015;27(1):38-40.

3. Segovia Gómez T. Manejo del tejido desvitalizado en heridas crónicas: el desbridamiento cortante. Todoheridas. 2010;1(2):30-2.

4. Chaverri Fierro D. Hipergranulación en heridas crónicas: un problema ocasional pero no infrecuente. Gerokomos. 2007;18(3):150-4.
5. Consenso Internacional. Uso adecuado de los apósitos de plata en las heridas. Consenso del grupo de trabajo de expertos. London: Wounds International; 2012.

6. European Wound Management Association (EWMA). Position Document: Management of wound infection. London: MEP; 2006.

7. European Wound Management Association (EWMA). Documento de Posicionamiento: Heridas de difícil cicatrización: un enfoque integral. Londres: MEP; 2008.

8. International consensus. Optimising wellbeing in people living with a wound. An expert working group rewiew. London: Wounds International; 2012
9. Taylor G, Pan WR. Angiosomes of the leg: Anatomic Study and Clinical Implications. Plast Reconstr Surg. 1998;102(3):599-616.

10. Rodríguez Ramírez R, González Tuero JH. Métodos alternativos para el tratamiento de pacientes con heridas infectadas. Medisan. 2011;15(4):503. 